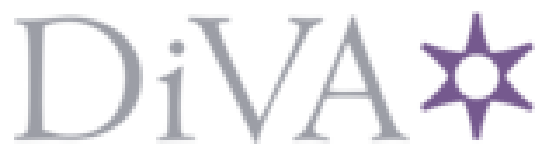

http://www.diva-portal.org

This is the published version of a paper published in Social behavior and personality.

Citation for the original published paper (version of record):

Vishwanatha, K., Hakelind, C., Steinvall, A., Svensson, J., Deutschmann, M. (2021) Interpersonal complementarity and gender: Contextual influences on perception of personality

Social behavior and personality, 49(6): e9812

https://doi.org/10.2224/sbp.9812

Access to the published version may require subscription.

N.B. When citing this work, cite the original published paper.

Permanent link to this version:

http://urn.kb.se/resolve?urn=urn:nbn:se:oru:diva-93276 


\title{
Interpersonal complementarity and gender: Contextual influences on perception of personality
}

\author{
Kalyani Vishwanatha ${ }^{1}$, Camilla Hakelind ${ }^{1}$, Anders Steinvall ${ }^{2}$, Johan Svensson ${ }^{3}$, Mats Deutschmann ${ }^{4}$ \\ ${ }^{1}$ Department of Psychology, Umeå University, Sweden \\ ${ }^{2}$ Department of Language Studies, Umeå University, Sweden \\ ${ }^{3}$ Department of Statistics, Umeå School of Business, Economics, and Statistics, Umeå University, Sweden \\ ${ }^{4}$ School of Humanities, Education, and Social Sciences, Örebro University, Sweden
}

How to cite: Vishwanatha, K., Hakelind, C., Steinvall, A., Svensson, J., \& Deutschmann, M. (2021). Interpersonal complementarity and gender: Contextual influences on perception of personality. Social Behavior and Personality: An international journal, 49(6), e9812

Contextual influences have long been recognized as an important factor explaining individual differences in perception of personality traits. In this study we investigated whether interpersonal complementarity creates a context for the perception of personality traits, and whether gender stereotypes play a role in the process. Participants were 205 students taking a personality psychology course. They evaluated personality traits in the context of observing an interpersonal exchange that reflected complementarity. Among the respondents, 103 made the evaluation based on a gender stereotypical exchange (dominant male-submissive female) and 102 based their evaluation on a gender counterstereotypical exchange (dominant female-submissive male). Results reveal that interpersonal context had a stronger influence on ratings of conscientiousness, openness, and emotional stability traits than it did on extraversion and agreeableness trait ratings. Furthermore, openness and conscientiousness were particularly susceptible to gender-based stereotypes in the context of interpersonal complementarity. These results suggest that both interpersonal complementarity and gender stereotypes influence the perception of personality traits, but that they do so in a way that is unique to each trait.

\section{Keywords}

interpersonal complementarity; interpersonal exchange; gender stereotypes; social roles; perception of personality traits; Big Five personality traits

An integral part of social interaction is understanding the personalities of other people. A theoretical framework that is often utilized in this endeavor is the five factor theory of personality, according to which it is claimed that personality descriptors are almost completely accounted for by five robust factors: neuroticism (also termed emotional stability), extraversion, openness, agreeableness, and conscientiousness (McCrae \& Costa, 2008). However, as proponents of the theory themselves point out, traits are not merely consistencies in overt behavior; rather, they are complex structures with cognitive, interpersonal, motivational, and stylistic components (McCrae \& Costa, 1996). Although basic tendencies are the raw material of personality, they interact dynamically with several elements, such as self-concept and situational demands, to produce the overt behaviors that humans perceive.

The social role with which an individual identifies has often been described as an objective construct relevant to both self-concept and situational demands. For instance, Roberts (2007) described a social role as a "position agreed upon by all parties that defines the way an individual relates to his/her social group" 
(p. 1072), and suggested that the many features of a role make it ideal to contextualize personality traits. Scholars have reported systematic variation in the Big Five traits as a function of social roles. For example, Sheldon et al. (1997) argued that in the context of a large degree of stability of traits across roles, there is enough meaningful evidence to warrant attention to variance across different roles. Although such variation across roles implies that people's understanding of themselves is influenced by the social category in which they place themselves, Roberts (2007) also pointed out that roles are used by others to ascribe characteristics to individuals, regardless of actual changes manifested by the individual.

In situations involving interaction with other people, identification with a particular social role meshes with the construct of interpersonal complementarity (Moskowitz et al., 2007). Interpersonal theorists have long argued that any interpersonal style tends to evoke a predictable set of behaviors or responses from others, referred to as complementary behaviors. According to this view, it is assumed that every behavior carries information regarding how the other person is to respond; thus, each behavior elicits or constrains the subsequent behavior of others (Tracey, 1994). An interaction is complementary when a person's demonstrated level of affiliation elicits similar (or correspondent) levels of affiliation from others, and when a person's demonstrated level of control/status elicits opposite (or reciprocal) levels of control/status from others. Thus, it is theorized (Kiesler, 1983; Sadler \& Woody, 2003) that friendly-submissive behavior elicits friendly-dominant responses (and vice versa), and hostile-dominant behavior evokes hostile-submissive responses (and vice versa). Hence, it could be proposed that the expression of personality traits occurs within the context of the social role the individual assumes, which, in turn, interacts with interpersonal complementarity.

When considering the control dimension of interpersonal complementarity, one potentially significant variable is gender. In traditional interpersonal theory, gender differences in complementarity are not emphasized, but later empirical studies addressed this issue, noting differences between men and women in the nature and outcome of complementarity (Ansell et al., 2008; Estroff \& Nowicki, 1992). None of these studies, however, have looked at the influence of gender stereotypes on complementarity.

Dominance begets submissiveness, and these two traits have stereotypically been associated with men and women, respectively (Prentice \& Carranza, 2002). Operating through both conscious and automatic processing (Wheeler \& Petty, 2001), stereotypes often have a profound impact on individual and societal levels. Knowledge based on a stereotype, if accessible, can be used to interpret a target's behavior (assimilation effects). If the stereotype is deemed to be unrepresentative, inappropriate, or biased, interpretation of the target behavior moves away from the stereotype (contrast effects; Lepore \& Brown, 2002).

The prevalence of gender stereotypes, and both the positive and negative consequences, have been widely studied and explained (Cheryan \& Bodenhausen, 2000; Fox \& Oxley, 2003; Heilman, 2012; Jacobs, 1991), and are understood to be pervasive across demographic groups and topics (Czopp et al., 2015; Nosek et al., 2007). A variety of contexts have been identified within which gender stereotypes can be activated, ranging from classroom situations to negotiations and anonymous computer communication (Huguet \& Régner, 2007; Kray et al., 2001; Postmes \& Spears, 2002). Taken together, the various threads of evidence indicate that contextual factors can influence the activation of and subsequent behavior based on gender stereotypes through several pathways that are specific to each contextual factor. Hence, making sense of stereotypical behavior in any given context builds on an understanding of contextual influences and the mechanism of the action of those influences on stereotypical outcomes.

Although gender differences in personality have been widely examined not only at the trait level but also at the aspect level (Weisberg et al., 2011), the presence and nature of gender stereotypes in the context of interpersonal complementarity have seldom been studied. One relevant study in this context was conducted by Dennhag et al. (2019), whose paradigm we have used in this study. In the study by Dennhag et al., 
interpersonal complementarity was evoked but was not included as a factor that could influence the perception of personality traits; nor was the role that gender stereotypes play in the perception of personality based on an interpersonal exchange. The focus of that study was restricted to an evaluation of the influence of gender-based stereotypes on observers' rating of the personality traits of the character in the dominant role. The purpose of this study was to extend the analyses conducted by Dennhag et al. We used the expected reciprocity on the control dimension in order to facilitate different combinations of dominance and submissiveness with gender stereotypical and counterstereotypical representations (dominant male-submissive female vs. dominant female-submissive male). Further, we investigated whether interpersonal complementarity creates a context that influences observers' perception of personality, and explored the interaction of complementarity with gender stereotypes in this process.

Given the universality of gender-based stereotypes, it could be hypothesized that these stereotypes are likely to operate within the context of interpersonal complementarity through mechanisms similar to those suggested by earlier researchers. Biernat (2012), for instance, argued that social categories to which individuals belong (e.g., gender, age, race) create different expectations for different groups. This, in turn, leads to shifting standards being adopted to evaluate different groups.

Another aspect of interest, then, would be if gender-based stereotypes activated within the context of interpersonal complementarity influence observers' perception of all traits in a similar manner. The literature cited above indicates such stereotypes might be activated; however, the extent and nature of the impact in interaction with interpersonal complementarity is likely to be different for each individual trait. Among other factors, the different patterns would be determined, in part, by the nature of the traits and their susceptibility to gender stereotypes. As such, we proposed the following hypotheses:

Hypothesis 1: Ratings of personality traits will be influenced by the control dimension of interpersonal complementarity.

Hypothesis 2: Gender stereotypes in interaction with interpersonal complementarity will differentially influence ratings of the Big Five personality traits.

\section{Method}

\section{Participants}

The sample consisted of 205 participants, of whom one subset rated the dominant character while the other subset rated the submissive character. All participants described their national identity as primarily Swedish, and all were attending an undergraduate university course in personality psychology that was taught in the English language. Table 1 shows the age and gender distribution of the participants. Both subsets were divided into two groups, one rating a male morph and the other rating a female morph. There were no significant differences between these subsets and groups regarding gender and age. 
Table 1. Age and Gender Distribution of the Participants

\begin{tabular}{|c|c|c|}
\hline & Judged & 's role \\
\hline & Submissive & Dominant \\
\hline Participants' & & \\
\hline $16-20$ & $16(15 \%)$ & $16(16 \%)$ \\
\hline $21-30$ & $79(76 \%)$ & $79(78 \%)$ \\
\hline $31-40$ & $9 \quad(9 \%)$ & $4 \quad(4 \%)$ \\
\hline $41-50$ & $0 \quad(0 \%)$ & $2 \quad(2 \%)$ \\
\hline Participants' & & \\
\hline Men & $37(36 \%)$ & $37(37 \%)$ \\
\hline Women & $66(63 \%)$ & $63(62 \%)$ \\
\hline Other & $1 \quad(1 \%)$ & $1 \quad(1 \%)$ \\
\hline
\end{tabular}

Note. $N=205$.

\section{Procedure}

We based our study partly on the material reported by Dennhag et al. (2019), with additional material assembled following the same procedure and using the same case scenarios as those described in their paper. Thus, the response case scenarios were built on a digitally updated matched-guise methodology. For details and procedures for the manipulations see Dennhag et al. and Lindvall-Östling et al. (2019). In short, our stimuli were two gender-altered scenarios based on a single recording, so that the gender of two people taking part in a mixed-sex conversation was switched for the different groups by digitally manipulating the voices. Therefore, the dominant character (henceforth referred to as CharacterDom) would sound like a woman in one version, but was manipulated to sound like a man in the other version. In the same way, the submissive character (henceforth CharacterSub) would sound like a man in one version and like a woman in the other version. To further support the mixed-sex nature of the dialogue, the sound was accompanied by neutral silhouette images of a male student and a female student interacting.

Table 2 shows the division and distribution of the participants into the four scenario conditions. Both subsets were randomly divided into two groups, one rating a male morph and the other rating a female morph of the same character.

Table 2. Division of the Total Sample Into Each of the Four Scenario Conditions

\begin{tabular}{lccc}
\hline & Male morph & Female morph & Total \\
\hline Dominant character & 55 & 46 & 101 \\
Submissive character & 56 & 48 & 104 \\
Total & 121 & 101 & 205 \\
\hline
\end{tabular}

Note. $N=205$.

\section{Materials and Measures}

The case scenario, composed of four short dialogic scenes, captured the chores of two students working on their joint degree project. In the dialogue, CharacterDom comes across as more dominant, self-assured, and 
demanding, whereas CharacterSub comes across as more submissive and insecure. The fact that both case versions were based on the same recording ensured the identical nature of critical aspects for the impressions of the dialogue and the judgment of its participants, such as intonation and force.

Neither discussions with the participants nor responses to a postsurvey check suggested that they suspected the voices had been manipulated. Control questions in the response survey revealed that there was no confusion with regard to the gender of CharacterDom and CharacterSub in the two versions of the scenario. To ensure that the participants perceived the interpersonal role of the characters as intended, the character was rated on the levels of their dominance and submissiveness on a scale from $\mathrm{o}=$ completely disagree to 10 = completely agree. In terms of means and 95\% confidence intervals (CI), CharacterDom was rated as more dominant, $M=7.34,95 \%$ CI $[6.90,7.77$ ] and less submissive, $M=1.35,95 \%$ CI [0.99, 1.71], and CharacterSub was rated as less dominant, $M=1.59,95 \%$ CI $[1.16,2.02]$ and more submissive, $M=8.20$, $95 \%$ CI $[7.87,8.53]$.

Immediately after the participants had listened to the scenario, they were asked to rate the personality of one of the two characters in the scenario via the Ten-Item Personality Inventory (TIPI; Gosling et al., 2003). The TIPI is an abbreviated way of assessing the Big Five domains, and is a widely used personality inventory with good test-retest reliability and adequate levels of convergent validity, as well as assigned norms for various age groups (Gosling et al., 2003). Each of the five personality traits (extraversion, agreeableness, conscientiousness, emotional stability, and openness) is itemized twice, and items are rated on a 7-point Likert scale ranging from $1=$ disagree strongly to $7=$ agree strongly.

A crucial aspect of a matched-guise design is that the participants are initially unaware of the true purpose of the exercise. To achieve this goal, the task was carried out as an assignment in a personality psychology course during which students listened to the scenario to later be able to discuss personality factors and social behavior. Because the participants were not made aware of the true purpose of the study until after the study was complete, they gave their informed consent in a postsurvey, when the full picture of the research objectives had been presented to them and discussed. Data from those who chose not to give their informed consent at that point were deleted. The project was approved by the Swedish Ethical Review Authority.

\section{Data Analysis}

To verify the first hypothesis we conducted a descriptive analysis of scores on each of the five traits, the results of which we compared to norms (Gosling et al., 2003). For comparison across traits, the distance of the respective sample means from the normative mean in terms of standard deviation units of the normative population was considered. Scores that differed by more than one standard deviation unit were considered to be substantially different from the norm. To examine the second hypothesis, an analysis of variance (ANOVA) was conducted for each of the five responses: extraversion, agreeableness, conscientiousness, emotional stability, and openness. The model was defined by the factors of interpersonal complementarity (submissive, dominant), perceived gender of the characters (man, woman), and the interaction between those factors, as well as the gender of the participants (man, woman). One participant who chose the gender label "other" was removed from this analysis. Effect sizes are presented as partial eta squared values $\left(\eta_{\mathrm{p}}{ }^{2}\right)$. Marginal estimated means were used for comparison between factor levels. Model assumption was evaluated with residual analysis. For some responses, the assumption of homoscedasticity of variance was violated. Therefore, a complementary sensitivity analysis was carried out via a bootstrapping analysis, with 1,000 resamples stratified on the factors in the ANOVA. The $p$ values derived with and without the bootstrapping procedure are presented in the tables. Throughout the report, significance was set at $p<.05$.

\section{Results}

Table 3 presents the means and standard deviations of the normative population in the age range of 20 to 40 years. Mean values and confidence intervals for our study sample are also shown. 
Table 3. Normative Values of the Big Five Personality Traits for the Dominant and Submissive Subsets

\begin{tabular}{lccc}
\hline Trait & Normative value* & $\begin{array}{c}\text { Dominant subset } \\
(n=101)\end{array}$ & $\begin{array}{c}\text { Submissive subset } \\
(n=104)\end{array}$ \\
\cline { 2 - 4 } & $M(S D)$ & $M[95 \% \mathrm{CI}, L L, U L]$ & $M[95 \% \mathrm{CI}, L L, U L]$ \\
\hline Extraversion & $4.44(1.45)$ & $3.24[3.10,3.39]$ & $4.30[4.06,4.53]$ \\
Agreeableness & $5.23(1.11)$ & $4.26[4.13,4.40]$ & $5.37[5.16,5.59]$ \\
Conscientiousness & $5.40(1.32)$ & $3.83[3.67,3.98]$ & $3.34[3.10,3.58]$ \\
Emotional stability & $4.83(1.42)$ & $3.84[3.68,3.99]$ & $2.45[2.21,2.70]$ \\
Openness & $5.38(1.07)$ & $3.63[3.48,3.79]$ & $4.02[3.84,4.20]$ \\
\hline
\end{tabular}

Note. ${ }^{*}$ Gosling et al. (2003). $L L=$ lower limit; $U L=$ upper limit.

The ANOVA results shown in Table 4 provide statistical support for the interaction between the perceived gender (man or woman) of the character and the interpersonal complementarity role of the character (dominant or submissive) for perception of the personality traits conscientiousness $(p=.04)$ and openness $(p<$.001). However, there was no significant interaction effect for the perception of extraversion, agreeableness, or emotional stability (see Appendix 1). Comparison of factor levels can be found in Appendix 2.

Table 4. Results of the Analyses of Variance Estimating Influence of Character's Gender and Interpersonal Style on Participants' Rating of the Personality Traits of Conscientiousness and Openness

\begin{tabular}{|c|c|c|c|c|}
\hline & \multicolumn{4}{|c|}{ Personality traits } \\
\hline & \multicolumn{4}{|c|}{ Conscientiousness } \\
\hline & $F(1,198)$ & $p$ & $p$ (bootstrapped) & $\eta_{\mathrm{p}}^{2}$ \\
\hline Character's gender & 5.25 & .023 & .026 & .026 \\
\hline Complementarity & 10.13 & .002 & .001 & .049 \\
\hline Character's gender $\times$ Complementarity & 4.26 & .040 & .037 & .021 \\
\hline \multirow[t]{2}{*}{ Participant's gender } & 0.02 & .890 & .900 & .000 \\
\hline & \multicolumn{4}{|c|}{ Openness } \\
\hline Character's gender & 5.98 & .015 & .015 & .029 \\
\hline Complementarity & 13.59 & $<.001$ & .002 & .064 \\
\hline Character's gender $\times$ Complementarity & 16.70 & $<.001$ & .002 & .078 \\
\hline Participant's gender & 1.86 & .171 & .112 & .009 \\
\hline
\end{tabular}

Note. Conscientiousness, $R^{2}=.095 ;$ openness, $R^{2}=.161$.

${ }^{*} p<.05 .{ }^{* *} p<.01$.

CharacterSub was seen as less conscientious than the dominant counterpart, regardless of gender. However, the male morph of CharacterSub showed a significantly lower rating for conscientiousness, compared to that 
for the female morph of CharacterSub (Figure 1a). Openness, on the other hand, showed a completely different pattern for the male morph as compared to the female morph. Whereas the female morph of CharacterSub was seen as being more open compared to the character that took the dominant role, a male morph maintained similar ratings irrespective of whether the interpersonal complementarity style was dominant or submissive (see Figure 1b).

(a) Conscientiousness

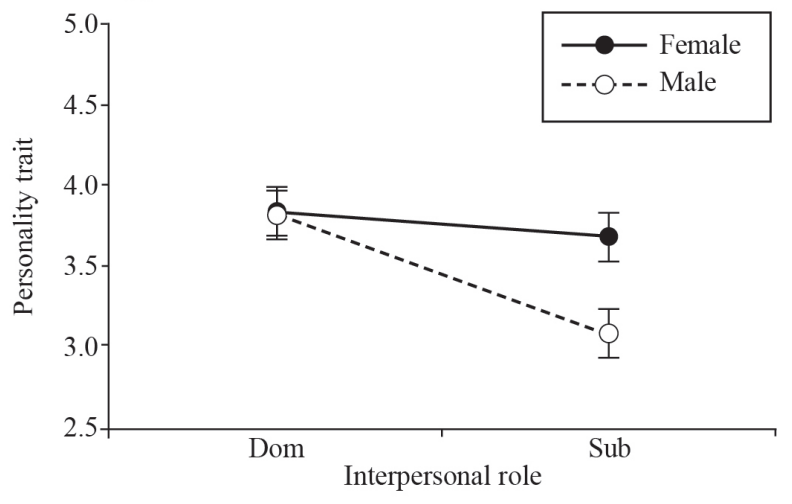

(b) Openness

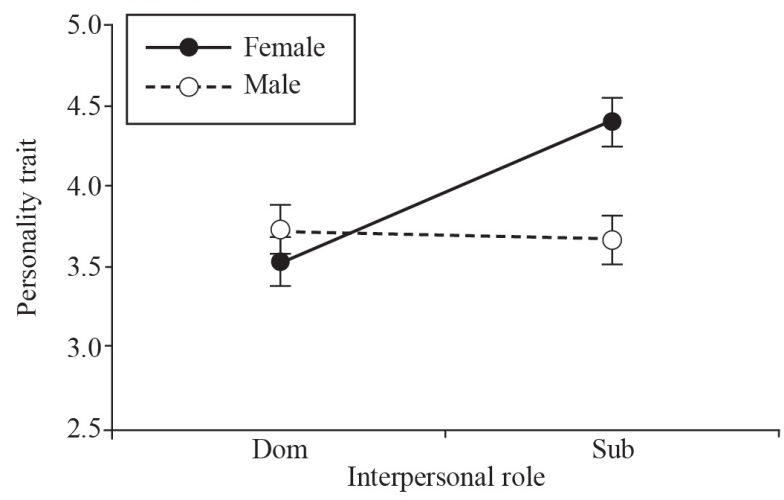

Figure 1. Interaction Between Interpersonal Role and Perceived Gender of the Rated Character for the Personality Traits of (a) Conscientiousness and (b) Openness

\section{Discussion}

We investigated whether interpersonal complementarity creates a context for the perception of personality traits, and explored the interaction of complementarity with gender stereotypes in this process. Participants evaluated personality traits in the context of listening to an interpersonal exchange that reflected complementarity under a gender stereotypical (dominant male-submissive female) or counterstereotypical condition (dominant female-submissive male).

\section{Rating of the Submissive Character}

The evaluation of personality was carried out in the context of a character perceived to be submissive interacting with a character perceived to be dominant. As expected, the participants' scores revealed different patterns for the five traits evaluated. Compared to the normative values assigned to people in the age group between 20 and 50 years (Gosling et al., 2003), our participants gave similar scores for their perception of two of the traits, extraversion and agreeableness; however, their scores for the perception of the other three traits of conscientiousness, emotional stability, and openness were considerably lower than the assigned normative values.

The task characteristics and the context created around interpersonal complementarity in our study provide a possible explanation for this variability. In our scenario, the interpersonal interaction began with a discussion of an unfavorable outcome with subsequent analysis of the potential reasons for the outcome. The trait of conscientiousness naturally assumes salience in this context; a lower level of conscientiousness of the character taking the submissive role becomes highlighted as an obvious explanation for the lessfavorable outcome because of the insinuations of the character taking the dominant role. This unpleasant situation also provides ample opportunity to evaluate emotional stability as a trait, with the possibility of reduced emotional stability being the most likely conclusion at which the listener would arrive. Finally, the 
discussion surrounding ways to remedy the situation would also provide information that the listener could use to evaluate the trait of openness.

\section{Rating of the Dominant Character}

CharacterDom was indeed perceived by the participants as being dominant. Comparison with the normative patterns revealed similar scores for perceptions of the traits of extraversion, agreeableness, and emotional stability, whereas perceptions of the traits of conscientiousness and openness yielded substantially lower scores. Again, it appears that the perception of the traits of conscientiousness and openness is steered by the demands of the circumstance, in which a less-than-favorable situation is highlighted with subsequent efforts to ensure a positive resolution.

In contrast to CharacterSub, however, scores for perception of CharacterDom for the trait of emotional stability were similar to the assigned normative mean. In theorizing on the determinants of perceived dominance or submissiveness in social situations, Hareli et al. (2009) discussed the importance of expressing different emotions. Our results seem to suggest an influence in the opposite direction, that is, how the expression of emotions is perceived is influenced by the context of established dominance or submissiveness.

Taken together, two conclusions can be drawn from the data reported above. First, not all traits are evaluated objectively to the same extent in all contexts. Observers are more likely to evaluate certain traits based on situational information, and ratings of these traits are likely to vary from suggested normative values, whereas other traits for which no contextual clarifications are received do retain values closer to the suggested normative values. Second, the control dimension of the interpersonal context may influence observers' ratings of certain traits. This, in turn, seems to imply that the absolute values of observers' ratings are less important by themselves; rather, it is the interpretation of these values within the context created that lends itself to a deeper understanding of the complex situation. Thus, our first hypothesis was supported by the results.

Certain gender-based trends in the perception of personality traits are also evident from Table 4. The scores for CharacterSub portrayed as a woman were higher on all five traits compared to when the same character was portrayed as a man. This is in line with the findings of researchers who examined gender differences in personality traits (Schmitt et al., 2008), with the exception of emotional stability. In prior studies women (vs. men) self-reported higher neuroticism and, consequently, lower emotional stability. The results of this study, however, present a contradictory perception that could potentially be the result of a gender stereotype effect. Particularly evident is a contrast effect, in that an impression opposite to that of the stereotypical response is evoked. We would be interested, then, to consider why, of the five traits we evaluated in our study, emotional stability was the only one to evoke a contrast effect, whereas the others evoked an assimilative effect. Awareness of gender-based stereotypes and of the potential for gender discrimination is quite widespread today. Of all the five traits assessed in the TIPI, an observer could see emotional stability (or lack thereof) as more likely to lead to discrimination based on stereotyping. This, in turn, could lead to an assumption of bias or inappropriateness when the evaluation is of the stereotype itself. As Lepore and Brown (2002) hypothesized, contrast effects may be evoked if the observer deems the stereotype to be unrepresentative, inappropriate, or biased. This could explain the contrast effect we found regarding this one trait.

A natural follow-up evaluation from the gender perspective, then, would be to analyze which perceived traits of personality are more likely to be susceptible to gender stereotypes in the context of interpersonal complementarity. The interaction shown in the ANOVA model helps shed light on this. For the traits of conscientiousness and openness, significant gender differences in variance between the dominant and submissive characters in the versions imply that in the context of interpersonal complementarity, the participants' perception of these two traits was more susceptible to stereotypical interpretations based on 
gender than were their perceptions of the other three traits. Previous research on gender differences in personality traits stands in contrast to this result in our study, with gender differences being obvious for the traits of extraversion, agreeableness, and emotional stability (Weisberg et al., 2011). This seems to suggest that the context provided by interpersonal complementarity in interaction with gender stereotypes renders gender-based influences nonsignificant when applied to the perception of these three traits. For the traits of conscientiousness and openness, Weisberg et al. (2011) again reported a result contradictory to that in our study, with no significant differences observed between the two genders. Elaborating on explanations for the lack of gender differences observed regarding these two traits, the authors pointed to the aspects that make up these traits and suggested variable susceptibility of the component aspects as a feature that masks the visibility of overall gender differences.

By extension, it can be hypothesized that the context within which an analysis is carried out plays a powerful role in determining the extent to which gender trends become apparent in the perception of the overall trait. This is by virtue of varying susceptibility of the component aspects as the context shifts. For instance, according to Weisberg et al. (2011), women are likely to be more orderly than are men, but men are likely to be more industrious than are women; thus, no overall difference would be observed on the trait of conscientiousness. In the context of interpersonal complementarity, when using the same analysis a submissive man would be rated in the context of an interaction with a dominant woman (or vice versa) instead of the man being rated solely in terms of conscientiousness. In a specific context, a subjective standard may be created that leads to a perception that differs from the perception that would result from an objective comparison. According to the shifting standards model (Biernat, 2012), this is likely to create a contrast effect, which could account for the significant difference our results show in the perception of these two traits.

We were also interested in the pattern of differences we found in the participants' perception of the conscientiousness and openness traits. The participants perceived the characters in the submissive role, whether male or female morphs, as being less conscientious than their dominant counterparts. However, they rated the male morph of CharacterSub significantly lower on conscientiousness compared to the female version of CharacterSub (Figure 1a). Thus, a woman in a submissive role who was interacting with a man in a dominant role was rated more favorably than a man in a submissive role who was interacting with a woman in a dominant role. On the other hand, the pattern of results for male and female versions for the trait of openness to experience was completely different. Whereas participants perceived the female version of CharacterSub as being more open compared to the female version of CharacterDom, male versions were rated similarly irrespective of whether their interpersonal style was dominant or submissive (Figure 1b).

Taken together, three strands of evidence supported our second hypothesis: (a) there was a contrast effect of gender stereotypes only for the participants' perception of the characters' emotional stability; (b) there was greater susceptibility for participants to form gender-based stereotypes in the context of interpersonal complementarity only for their perception of the characters' conscientiousness and openness; and (c) there were differing patterns of the influence of interpersonal complementarity in interaction with gender stereotypes in the participants' perception of characters' openness and conscientiousness.

\section{Implications, Applications, and Limitations of the Study}

These arguments bring up the question of the relative importance of norms and situational information in interpreting behavior. A superficial glance at our results might suggest that norms are of marginal utility, but it is important to acknowledge the baseline provided by normative values. Contextual information provides only a framework to interpret deviations (or lack thereof) from existing normative understanding. Norms and contextual influences, accordingly, can be regarded as two aspects of the same situation, neither of which, by itself, provides a complete understanding. The results also indicate that, while submissiveness was most often evoked by dominance, and vice versa (as suggested by the complementarity principle), individuals retain their own distinctive identity, over and above the evoked complementarity, based on 
belongingness to several social categories (e.g., gender).

Our results could have applications of significance in personnel recruitment and team-building contexts, by highlighting the importance of not just complementarity in personality but also other interacting contextual factors, such as gender stereotypes, as well. The results also suggest the importance of considering both the overall context and the fit of an individual to the context, rather than focusing solely on individual traits.

The results of this study offer some thought-provoking insights regarding the influence of interpersonal complementarity and gender stereotypes, but certain methodological strengths and limitations can be noted. The design was strengthened by checks to ensure that the dominant and submissive characters were perceived as intended, by introducing a rating for participants to complete. In addition, these ratings also reflected that the participants were not ambivalent about the interpersonal style, as they rated the character as being both high on dominance and also low on submissiveness (and vice versa). However, although the sample was a largely homogenous group composed of Swedish students who were part of a course in personality psychology, there was a certain amount of variability in their academic background as it was a freestanding course open to students from all disciplines. For this reason, their awareness of and exposure to the topics of gender and stereotypes may have varied, depending on their field of study. The sample was also collected over several semesters, not at one time point. This could have led to variability in the conditions for different groups of students. Although the sample size was considerably large, a bigger sample would have further reduced the likelihood of Type II error occurring. Furthermore, the design of the case scenario restricted the analysis to the control dimension of interpersonal complementarity. An analysis of the affiliation dimension might add to a better understanding of the contextual influences of interpersonal complementarity.

In sum, the results of this study underline the fact that perception of personality is characterized by the same basic dichotomy that epitomizes the construct of personality, namely, that personality is both stable and evolving. The trait contributes to stability whereas the context creates the evolution constantly reflected in the perception of personality.

\section{Acknowledgments}

This study was supported by the Swedish Research Council (721-2014-1972).

\section{References}

Ansell, E. B., Kurtz, J. E., \& Markey, P. M. (2008). Gender differences in interpersonal complementarity within roommate dyads. Personality and Social Psychology Bulletin, 34(4), 502-512.

https://doi.org/10.1177/0146167207312312

Biernat, M. (2012). Stereotypes and shifting standards. Forming, communicating, and translating person impressions. In P. Devine \& A. Plant (Eds.), Advances in experimental social psychology (Vol. 45, pp. 1-59). Academic Press.

https://doi.org/10.1016/B978-0-12-394286-9.00001-9

Cheryan, S., \& Bodenhausen, G. V. (2000). When positive stereotypes threaten intellectual performance: The psychological hazards of "model minority" status. Psychological Science, 11(5), 399-402. https://doi.org/10.1111/1467-9280.00277

Czopp, A. M., Kay, A. C., \& Cheryan, S. (2015). Positive stereotypes are pervasive and powerful. Perspectives on Psychological Science, 10(4), 451-463.

https://doi.org/10.1177/1745691615588091 
Dennhag, I., Steinvall, A., Hakelind, C., \& Deutschmann, M. (2019). Exploring gender stereotypes about interpersonal behavior and personality factors using digital matched-guise techniques. Social Behavior and Personality: An international journal, 47(8), Article e8150.

https://doi.org/10.2224/sbp.8150

Estroff, S. D., \& Nowicki, S., Jr. (1992). Interpersonal complementarity, gender of interactants, and performance on puzzle and word tasks. Personality and Social Psychology Bulletin, 18(3), 351-356.

https://doi.org/10.1177/0146167292183012

Fox, R. L., \& Oxley, Z. M. (2003). Gender stereotyping in state executive elections: Candidate selection and success. The Journal of Politics, 65(3), 833-850.

https://doi.org/10.1111/1468-2508.00214

Gosling, S. D., Rentfrow, P. J., \& Swann, W. B., Jr. (2003). A very brief measure of the Big-Five personality domains. Journal of Research in Personality, 37(6), 504-528.

https://doi.org/10.1016/So092-6566(03)00046-1

Hareli, S., Shomrat, N., \& Hess, U. (2009). Emotional versus neutral expressions and perceptions of social dominance and submissiveness. Emotion, 9(3), 378-384.

https://doi.org/10.1037/a0015958

Heilman, M. E. (2012). Gender stereotypes and workplace bias. Research in Organizational Behavior, 32, $113-135$.

https://doi.org/10.1016/J.RIOB.2012.11.003

Huguet, P., \& Régner, I. (2007). Stereotype threat among schoolgirls in quasi-ordinary classroom circumstances. Journal of Educational Psychology, 99(3), 545-560.

https://doi.org/10.1037/0022-0663.99.3.545

Jacobs, J. E. (1991). Influence of gender stereotypes on parent and child mathematics attitudes. Journal of Educational Psychology, 83(4), 518-527.

https://doi.org/10.1037/0022-0663.83.4.518

Kiesler, D. J. (1983). The 1982 interpersonal circle: A taxonomy for complementarity in human transactions. Psychological Review, 9o(3), 185-214.

https://doi.org/10.1037/0033-295X.90.3.185

Kray, L. J., Thompson, L., \& Galinsky, A. (2001). Battle of the sexes: Gender stereotype confirmation and reactance in negotiations. Journal of Personality and Social Psychology, 8o(6), 942-958.

https://doi.org/10.1037/0022-3514.80.6.942

Lepore, L., \& Brown, R. (2002). The role of awareness: Divergent automatic stereotype activation and implicit judgment correction. Social Cognition, 20(4), 321-351.

https://doi.org/10.1521/soco.20.4.321.19907

Lindvall-Östling, M., Deutschmann, M., \& Steinvall, A. (2019). "Oh it was a woman! Had I known I would have reacted otherwise!": Developing digital methods to switch identity-related properties in order to reveal linguistic stereotyping. In S. Bagga-Gupta, G. Messina Dahlberg, \& Y. Lindberg (Eds.), Virtual sites as learning spaces (pp. 207-239). Palgrave Macmillan.

https://doi.org/10.1007/978-3-030-26929-6_8

McCrae, R. R., \& Costa, P. T. (1996). Toward a new generation of personality theories: Theoretical contexts for the five factor model. In J. S. Wiggins (Ed.), The five factor model of personality: Theoretical perspectives (pp. 51-87). The Guilford Press.

McCrae, R. R., \& Costa, P. T., Jr. (2008). The five-factor theory of personality. In O. P. John, R. W. Robins, \& L. A. Pervin (Eds.), Handbook of personality: Theory and research (pp. 159-181). The Guilford Press. https://bit.ly/3u4PF96 
Moskowitz, D. S., Ho, M. R., \& Turcotte-Tremblay, A.-M. (2007). Contextual influences on interpersonal complementarity. Personality and Social Psychology Bulletin, 33(8), 1051-1063.

https://doi.org/10.1177/0146167207303024

Nosek, B. A., Smyth, F. L., Hansen, J. J., Devos, T., Lindner, N. M., Ranganath, K. A., ... Banaji, M. R. (2007). Pervasiveness and correlates of implicit attitudes and stereotypes. European Review of Social Psychology, 18(1), 36-88.

https://doi.org/10.1080/10463280701489053

Postmes, T., \& Spears, R. (2002). Behavior online: Does anonymous computer communication reduce gender inequality? Personality and Social Psychology Bulletin, 28(8), 1073-1083.

https://doi.org/10.1177/01461672022811006

Prentice, D. A., \& Carranza, E. (2002). What women and men should be, shouldn't be, are allowed to be, and don't have to be: The contents of prescriptive gender stereotypes. Psychology of Women Quarterly, 26(4), $269-281$.

https://doi.org/10.1111/1471-6402.to1-1-00o66

Roberts, B. W. (2007). Contextualizing personality psychology. Journal of Personality, 75(6), 1071-1082. https://doi.org/10.1111/j.1467-6494.2007.00467.x

Sadler, P., \& Woody, E. (2003). Is who you are who you're talking to? Interpersonal style and complementarity in mixed-sex interactions. Journal of Personality and Social Psychology, 84(1), 80-96.

https://doi.org/10.1037/0022-3514.84.1.80

Schmitt, D. P., Realo, A., Voracek, M., \& Allik, J. (2008). Why can't a man be more like a woman? Sex differences in Big Five personality traits across 55 cultures. Journal of Personality and Social Psychology, 94(1), 168-182.

https://doi.org/10.1037/0022-3514.94.1.168

Sheldon, K. M., Ryan, R. M., Rawsthorne, L. J., \& Ilardi, B. (1997). Trait self and true self: Cross-role variation in the Big-Five personality traits and its relations with psychological authenticity and subjective well-being. Journal of Personality and Social Psychology, 73(6), 1380-1393.

https://doi.org/10.1037/0022-3514.73.6.1380

Tracey, T. J. (1994). An examination of the complementarity of interpersonal behavior. Journal of Personality and Social Psychology, 67(5), 864-878.

https://doi.org/10.1037/0022-3514.67.5.864

Weisberg, Y. J., DeYoung, C. G., \& Hirsh, J. B. (2011). Gender differences in personality across the ten aspects of the Big Five. Frontiers in Psychology, 2, Article 178.

https://doi.org/10.3389/fpsyg.2011.00178

Wheeler, S. C., \& Petty, R. E. (2001). The effects of stereotype activation on behavior: A review of possible mechanisms. Psychological Bulletin, 127(6), 797-826.

https://doi.org/10.1037/0033-2909.127.6.797 


\section{Appendix 1}

Analyses of Variance Estimating the Influence of Character's Gender and Interpersonal Style on Participants' Rating of the Personality Traits of Extraversion, Agreeableness, and Emotional Stability

\begin{tabular}{|c|c|c|c|c|}
\hline & \multicolumn{4}{|c|}{ Personality traits } \\
\hline & \multicolumn{4}{|c|}{ Extraversion } \\
\hline & $F(1,198)$ & $p$ & $p$ (bootstrapped) & $\eta_{p}^{2}$ \\
\hline Character's gender & 1.36 & .24 & .24 & .007 \\
\hline Complementarity & 54.69 & $<.001$ & .001 & .216 \\
\hline Character's gender $\times$ Complementarity & 0.00 & .96 & .96 & .000 \\
\hline \multirow[t]{2}{*}{ Participant's gender } & 0.39 & .53 & .53 & .002 \\
\hline & \multicolumn{4}{|c|}{ Agreeableness } \\
\hline Character's gender & 0.39 & .53 & .54 & .002 \\
\hline Complementarity & 70.77 & $<.001$ & .001 & .263 \\
\hline Character's gender $\times$ Complementarity & 0.13 & .72 & .72 & .001 \\
\hline \multirow[t]{2}{*}{ Participant's gender } & 0.07 & .80 & .81 & .000 \\
\hline & \multicolumn{4}{|c|}{ Emotional stability } \\
\hline Character's gender & 4.08 & .045 & .51 & .020 \\
\hline Complementarity & 91.33 & $<.001$ & .001 & .316 \\
\hline Character's gender $\times$ Complementarity & 3.37 & .07 & .09 & .017 \\
\hline Participant's gender & 2.76 & .10 & .14 & .017 \\
\hline
\end{tabular}

Note. Extraversion, $R^{2}=.223$; agreeableness, $R^{2}=.268$; emotional stability, $R^{2}=.348$. 


\section{Appendix 2}

Comparison of Participants' Ratings of Male and Female Characters Across Dominant and Submissive Interpersonal Roles

\begin{tabular}{|c|c|c|c|c|c|c|c|}
\hline \multirow[t]{2}{*}{ Trait } & \multirow{2}{*}{$\begin{array}{l}\text { Interpersonal } \\
\text { role }\end{array}$} & \multicolumn{2}{|c|}{ Gender } & \multirow[b]{2}{*}{$\begin{array}{c}\text { Diff } \\
M(95 \% \text { CI } L L, U L)\end{array}$} & \multirow[b]{2}{*}{$p$} & \multirow[b]{2}{*}{$\eta_{\mathrm{p}}^{2}$} & \multirow{2}{*}{$\begin{array}{c}\begin{array}{c}\text { Sensitivity } \\
\text { analysis }\end{array} \\
p \text {-boot }\end{array}$} \\
\hline & & $\begin{array}{c}\text { Men } \\
M(95 \% \text { CI } L L, U L)\end{array}$ & $\begin{array}{c}\text { Women } \\
M(95 \% \text { CI } L L, U L)\end{array}$ & & & & \\
\hline \multirow[t]{3}{*}{ Extraversion } & Dom & $3.18[2.91,3.45]$ & $3.36[3.06,3.65]$ & $\begin{array}{c}-0.17 \\
-0-57 \quad 0237\end{array}$ & .40 & .004 & .21 \\
\hline & Sub & $4.24[3.96,4,51]$ & $4.39[4.11,4.68]$ & $\begin{array}{c}-0.16 \\
{[-0.23,0,55]}\end{array}$ & .43 & .003 & .50 \\
\hline & Total & $3.71[3.52,3.90]$ & $3.87[3.66,4.08]$ & $\begin{array}{c}-0.17 \\
{[-0.44,0.11]}\end{array}$ & .24 & .007 & .24 \\
\hline \multirow[t]{3}{*}{ Agreeableness } & Dom & $4.20[3.95,4.45]$ & $4.34[4.06,4.61]$ & $\begin{array}{c}-0.13 \\
{[-0.50,0.24]}\end{array}$ & .49 & .002 & .34 \\
\hline & Sub & $5.35[5.10,5.60]$ & $5.38[5.12,5,65]$ & $\begin{array}{c}-0.03 \\
{[-0.40,0.33]}\end{array}$ & .85 & .000 & .89 \\
\hline & Total & $4.77[4.60,4.95]$ & $4.86[4.67,5.06]$ & $\begin{array}{c}-0.08 \\
{[-0.34,0.18]}\end{array}$ & .53 & .002 & .54 \\
\hline \multirow[t]{3}{*}{ Conscientiousness } & Dom & $3.81[3.54,4.09]$ & $3.84[3.54,4.15]$ & $\begin{array}{c}-0.03 \\
{[-0.44,0.37]}\end{array}$ & .88 & .000 & .84 \\
\hline & Sub & $3.06[2.78,3.34]$ & $3.68[3.39,3.98]$ & $\begin{array}{c}-0.63 \\
{[-1.02,-0.23]}\end{array}$ & .002 & .046 & .010 \\
\hline & Total & $3.43[3.24,3.63]$ & $3.76[3.55,3.98]$ & $\begin{array}{c}-0.33 \\
{[-0.61,-0.05]}\end{array}$ & .023 & .026 & .026 \\
\hline \multirow[t]{3}{*}{ Emotional stability } & Dom & $3.86[3.58,4.14]$ & $3.89[3.58,4.20]$ & $\begin{array}{c}-0.03 \\
{[-0.43,0.38]}\end{array}$ & .90 & .000 & .86 \\
\hline & Sub & $2.21[1.93,2.50]$ & $2.77[2.48,3.06]$ & $\begin{array}{c}-0.56 \\
{[-0.96,0.16]}\end{array}$ & .07 & .026 & .37 \\
\hline & Total & $3.04[2.84,3.23]$ & $3.33[3.12,3.54]$ & $\begin{array}{c}-0.29 \\
{[-0.58,0.07]}\end{array}$ & .45 & .020 & .51 \\
\hline \multirow[t]{3}{*}{ Openness } & Dom & $3.74[3.53,3.96]$ & $3.55[3.31,3.79]$ & $\begin{array}{c}0.19 \\
{[-0.13,0.51]}\end{array}$ & .24 & .007 & .23 \\
\hline & Sub & $3.69[3.47,3.91]$ & $4.44[4.21,4.67]$ & $\begin{array}{c}-0.75 \\
{[-1.06,-0.43]}\end{array}$ & $<.001$ & .099 & .001 \\
\hline & Total & $3.72[3.56,3.87]$ & $4.00[3.83,4.17]$ & $\begin{array}{c}-0.29 \\
{[-0.50,-0.05]}\end{array}$ & .015 & .029 & .015 \\
\hline
\end{tabular}

Note. Dom = dominant, $\mathrm{Sub}=$ submissive; $\mathrm{CI}=$ confidence interval; $L L=$ lower limit; $U L=$ upper limit. 